\title{
Utilization of Telehealth Services in Libya in Response to the COVID-19 Pandemic: Cross-sectional Analysis
}

Muhammed Elhadi ${ }^{1}$, MBBCh; Ahmed Msherghi ${ }^{1}$, MBBCh; Ahmed Elhadi ${ }^{1}$, MBBCh; Aimen Ashini ${ }^{1}$, MD; Ahmed Alsoufi ${ }^{1}$, MBBCh; Fatimah Bin Alshiteewi ${ }^{1}$, MBBCh; Amna Elmabrouk ${ }^{1}, \mathrm{MBBCh}$; Ali Alsuyihili ${ }^{1}, \mathrm{MBBCh}$; Alsafa Elgherwi ${ }^{1}$, MBBCh; Fatimah Elkhafeefi ${ }^{2}$, MBBCh; Sarah Abdulrazik ${ }^{1}$, MD; Ahmed Tarek ${ }^{1}$, MBBCh $^{2}$

\footnotetext{
${ }^{1}$ Faculty of Medicine, University of Tripoli, Tripoli, Libyan Arab Jamahiriya

${ }^{2}$ Faculty of Medicine, University of Benghazi, Benghazi, Libyan Arab Jamahiriya
}

\section{Corresponding Author:}

Muhammed Elhadi, MBBCh

Faculty of Medicine

University of Tripoli

Furnaj, University Road

Tripoli, 13275

Libyan Arab Jamahiriya

Phone: 218945196407

Email: muhammed.elhadi.uot@gmail.com

\begin{abstract}
Background: Health care systems in transitional countries have witnessed unprecedented challenges related to adequate and continuous health care provision during the COVID-19 pandemic. In many countries, including Libya, institutions and organizations have begun to implement telehealth technology for the first time. This serves to establish an alternative modality for direct physician-patient interviews to reduce the risk of COVID-19 transmission.
\end{abstract}

Objective: This study aimed to assess the usability of telehealth services in Libya and to provide an overview of the current COVID-19 scenario.

Methods: In this cross-sectional study, an anonymous web-based survey was administered to Libyan residents between April and May 2020. Participants were contacted through text messaging, emails, and social media. The survey items yielded information on the sociodemographic characteristics, availability and accessibility of health care services, effects of the COVID-19 pandemic on health care services, mental health status, and the feasibility and application of the telehealth system.

Results: We obtained 2512 valid responses, of which 1721 (68.5\%) were from females. The participants were aged 28.2 (SD 7.6) years, of whom 2333 (92.9\%) were aged <40 years, and 1463 (58.2\%) were single. Regarding the health care services and their accessibility, $786(31.1 \%)$ participants reported having a poor health status in general, and $492(19.6 \%)$ reported having a confirmed diagnosis of at least one chronic disease. Furthermore, 498 (19.9\%) participants reported varying degrees of difficulty in accessing health care centers, and $1558(62.0 \%)$ could not access their medical records. Additionally, $1546(61.6 \%)$ participants experienced problems in covering medical costs, and 1429 (56.9\%) avoided seeking medical care owing to financial concerns. Regarding the feasibility of the telehealth system, approximately half of the participants reported that telehealth services were useful during the COVID-19 pandemic, and 1545 (61.5\%) reported that the system was an effective means of communication and of obtaining health care services. Furthermore, 1435 (57.1\%) participants felt comfortable using the telehealth system, and $1129(44.9 \%)$ felt that they were able to express themselves effectively. Moreover, 1389 (55.3\%) participants found the system easy to understand, and 1354 (53.9\%) reported having excellent communication with physicians through the telehealth system. However, only 1018 (40.5\%) participants reported that communication was better with the telehealth system than with traditional methods.

Conclusions: Our study revealed high levels of usability and willingness to use the telemedicine system as an alternative modality to in-person consultations among the Libyan residents in this study. This system is advantageous because it helps overcome health care costs, increases access to prompt medical care and follow-up evaluation, and reduces the risk of COVID-19 transmission. However, internet connectivity and electricity issues could be a substantial barrier for many resource-limited communities, and further studies should address such obstacles. 
(JMIR Med Inform 2021;9(2):e23335) doi: 10.2196/23335

\section{KEYWORDS}

COVID-19; cross-sectional study; resource-limited countries; SARS-CoV-2; telehealth; telemedicine; transitional countries; usability

\section{Introduction}

Since December 2019, COVID-19 has disrupted health care systems in many countries $[1,2]$. SARS-CoV-2, the causative virus of the severe viral pneumonia COVID-19, has infected more than 14,000,000 individuals and resulted in approximately 600,000 deaths worldwide $[3,4]$.

The emergence of the COVID-19 pandemic has posed unprecedented challenges on health care systems in many countries, resulting in the cancellation of surgical procedures, closure of clinics, and an increase in the burden on health care services from patients with COVID-19 who require careful consideration and more care [5-7]. In response to this disruption, many countries have started implementing strategies to reduce the risk of disease transmission and to provide adequate health care services, especially among individuals with chronic diseases who need more care [8-11].

Therefore, many countries have started using telehealth services; that is, advanced technologies such as video, audio, and other means to provide health care services and promote the well-being of individuals while being physically distant from the health care provider [12-14]. Telehealth services offer several advantages to both patients and health care providers. The benefits of this system among patients include a shorter waiting time, a reduced need to travel long distances from their homes for health consultations, total avoidance of transport, and a reduced risk of infection, especially during the COVID-19 pandemic. The telehealth system offers several advantages to health care workers, including a marked reduction in patient interaction, the ability to assess patients with different diseases, the ability to perform follow-up evaluation and record outcomes, and a reduction in stress related to the COVID-19 pandemic.

The Libyan health care system operates primarily through public health centers and primary care centers, at which health services are provided at no cost. However, this manner of health care provision lacks sophisticated and advanced health services. In addition, a large number of private centers provide paid health services that may confer more advantages over traditional public health care services. However, these expensive private care services might represent a barrier to care provision among many Libyan residents. Although some large companies provide health insurance to their employees, such as policies that cover the main services provided by private health care centers, this provision is limited to a very specific portion of the population.

The Libyan health care system was not prepared for the COVID-19 pandemic. Hospitals and health care workers in Libya need better training and more resources to combat the pandemic, and there have been shortages of personal protective equipment, a lack of health services, and few prepared intensive care units $[15,16]$. These difficulties, along with the current ongoing civil war, pose challenges on the Libyan health care system, resulting in a high demand for urgent and determined action [17].

Many institutions and organizations have initiated telehealth programs for the first time during the COVID-19 pandemic in Libya to help patients avail of health care services and consultations without the need to visit hospitals and to reduce the risk of COVID-19 transmission. Since this is the first time telehealth services have been introduced in Libya, their usability by the Libyan population and their health-related effects need to be assessed, and the challenges faced by health care authorities and organizations in implementing these new strategies need to be determined. In this study, we aimed to assess the usability of telehealth services in Libya and to provide an overview of the current COVID-19 scenario.

\section{Methods}

\section{Participant Recruitment}

In this cross-sectional study, we distributed an anonymous web-based survey among Libyan residents between April and May 2020 via text message, email, and social media platforms. The inclusion criteria were that participants should be Libyan residents aged over 18 years. Incomplete questionnaires with $>30 \%$ missing data were excluded from the analysis. We marked essential questions with the "required" function to ensure high quality of the data collected.

\section{Measurement Tool}

The web-based survey was conducted in accordance with the Checklist for Reporting Results of Internet E-Surveys [18]. The first section of the survey included questions on demographic characteristics such as age, gender, social status, economic stability, residential status, smoking status, and general health. The second section of the survey comprised questions on the availability and accessibility of health care services, including the distance travelled to access nearest health care facility and the time taken to reach it, mode of transport available, and ability to cover medical costs. The third section comprised questions related to the effects of the COVID-19 pandemic on health care services. A subsequent section contained questions on mental health status, screening symptoms of anxiety and depression using the self-administered 9-item Patient Health Questionnaire (PHQ-9) [19,20], wherein a score of $\geq 15$ was considered the threshold for depression. The 7-item Generalized Anxiety Disorder scale [21] was used to assess anxiety, with a score of $\geq 15$ as the threshold for anxiety. The final section of the questionnaire assessed the usability of telehealth in accordance with the Telehealth Usability Questionnaire devised by Parmanto et al [22] and validated by Zhou et al [23]. The telehealth questionnaire was translated to Arabic by two independent translators using the forward-backward translation method. Any discrepancy in the translated versions was resolved through further discussion until consensus was reached. The translated 
questionnaire was piloted with 30 participants, and the internal consistency was determined from a Cronbach $\alpha$ of .74 in the translated Arabic version. The telehealth usability survey included 3 items on the usefulness of telehealth, 3 items on the ease of use and learnability, 4 items on interface quality, 4 items on the quality of interaction, 3 items on reliability, and 4 items on satisfaction. Each of these items was scored on a 3-point Likert scale ( $0=$ agree, $1=$ neutral, $2=$ disagree $)$.

\section{Statistical Analysis}

Descriptive statistics are presented as frequency and percentage values. Continuous variables are presented as mean (SD) values. We performed a chi-square test to investigate associations between basic study characteristics and gender. Statistical analyses were performed using SPSS software (version 25.0, IBM Corp). A $P$ value of $\leq .05$ was considered significant

\section{Ethical Considerations}

The study was approved by the Bioethics Committee of the Biotechnology Research Centre (Tripoli, Libya; 109.3-2020).
Participants provided written informed consent and their anonymity was maintained.

\section{Results}

\section{Participant Characteristics}

We obtained 2512 valid responses. In total, 1721 (68.5\%) respondents were female and 791 (31.5\%) were male. The study participants were aged 28.2 (SD 7.6) years. Most participants $(\mathrm{n}=2333,92.9 \%)$ were aged $<40$ years and $1463(58.2 \%)$ were single. In total, $766(30.5 \%)$ participants were students and constituted the majority of the cohort by occupation. A total of $492(19.6 \%)$ respondents reported having a chronic disease, $1137(45.3 \%)$ reported having an excellent health status, and $786(31.1 \%)$ reported having a poor health status. Table 1 summarizes the baseline demographic characteristics of the study population. We observed a significant association between gender and age $(P<.001)$, marital status $(P=.002)$, employment status $(P<.001)$, stable income $(P=.03)$, smoking status $(P<.001)$, chronic disease $(P=.02)$, and living arrangement $(P=.03)$. 
Table 1. Baseline demographic characteristics of the study population $(\mathrm{N}=2512)$.

\begin{tabular}{|c|c|c|c|c|}
\hline Variables & Total, n (\%) & Female (1721), n (\%) & Male $(\mathrm{n}=791), \mathrm{n}(\%)$ & $P$ value \\
\hline Age range (years) & & & & $<.001^{\mathrm{a}}$ \\
\hline $18-25$ & $1062(42.3)$ & $748(43.5)$ & $314(39.7)$ & \\
\hline $26-40$ & $1271(50.6)$ & $878(51.0)$ & $393(49.7)$ & \\
\hline$>40$ & $179(7.1)$ & $95(5.5)$ & $84(10.6)$ & \\
\hline Marital status & & & & $.002^{\mathrm{b}}$ \\
\hline Married & $971(38.7)$ & $707(41.1)$ & $264(33.4)$ & \\
\hline Single & $1463(58.2)$ & $960(55.8)$ & $503(63.6)$ & \\
\hline Divorced & $58(2.3)$ & $39(2.3)$ & $19(2.4)$ & \\
\hline Widowed/widower & $20(0.8)$ & $15(0.9)$ & $5(0.6)$ & \\
\hline Employment status & & & & $<.001^{\mathrm{a}}$ \\
\hline Student & $766(30.5)$ & $527(30.6)$ & $239(30.2)$ & \\
\hline Business and management & $180(7.2)$ & $119(6.9)$ & $61(7.7)$ & \\
\hline Engineering and manufacturing & $68(2.7)$ & $42(2.4)$ & $26(3.3)$ & \\
\hline Health care & $315(12.5)$ & $213(12.4)$ & $102(12.9)$ & \\
\hline Teaching and education & $266(10.6)$ & $205(11.9)$ & $61(7.7)$ & \\
\hline Science and pharmaceutical & $65(2.6)$ & $47(2.7)$ & $18(2.3)$ & \\
\hline Retails and sales & $12(0.5)$ & $3(0.2)$ & $9(1.1)$ & \\
\hline Homemaker & $377(15.0)$ & $327(19.0)$ & $50(6.3)$ & \\
\hline Laborer & $24(1.0)$ & $17(1.0)$ & $7(0.9)$ & \\
\hline Freelance & $54(2.1)$ & $10(0.6)$ & $44(5.6)$ & \\
\hline Retired & $4(0.2)$ & $2(0.1)$ & $2(0.3)$ & \\
\hline Unemployed & $316(12.6)$ & $177(10.3)$ & $139(17.6)$ & \\
\hline Other & $65(2.6)$ & $32(1.9)$ & $33(4.2)$ & \\
\hline Stable income & $846(33.7)$ & $556(32.3)$ & $290(36.7)$ & $.03^{\mathrm{b}}$ \\
\hline Smoking & $104(4.1)$ & $35(2.0)$ & $69(8.7)$ & $<.001^{\mathrm{a}}$ \\
\hline Having chronic disease & 492 (19.6) & $329(19.1)$ & $163(20.6)$ & $.02^{\mathrm{b}}$ \\
\hline Living arrangement & & & & $.03^{\mathrm{b}}$ \\
\hline With family & $2065(82.2)$ & $1396(81.1)$ & $669(84.6)$ & \\
\hline Alone & $447(17.8)$ & $325(18.9)$ & $122(15.4)$ & \\
\hline General health status & & & & .40 \\
\hline Excellent & $1137(45.3)$ & $766(44.5)$ & $371(46.9)$ & \\
\hline Very good & $61(2.4)$ & $44(2.6)$ & $17(2.1)$ & \\
\hline Good & $528(21.0)$ & $376(21.8)$ & $152(19.2)$ & \\
\hline $\mathrm{Bad}$ & $786(31.1)$ & $535(31.1)$ & $251(31.7)$ & \\
\hline
\end{tabular}

${ }^{\mathrm{a}} P<.001$.

${ }^{\mathrm{b}} P<.05$.

\section{Accessibility of Health Care Services}

Most participants reported an adequate level of ease in accessing health care centers, with $715(28.5 \%)$ responding with "very easy" and 1299 (51.7\%) responding with "easy." Regarding their mode of transport, almost half of the participants $(n=1140$,
45.4\%) reported driving their own car, and 1097 (43.7\%) hired a taxi or a private driver. In addition, 989 (39.4\%) respondents reported that it took them 15-30 minutes to reach a health care facility, whereas $804(32 \%)$ reported that they needed less than 15 minutes to reach their nearest facility. Furthermore, 1407 (56\%) participants reported that they could consult with a 
specialist physician within 2 days, whereas 1558 (62\%) reported that they could not access their medical records or files.

Most participants $(n=1546,61.6 \%)$ found it difficult to cover the costs of medical care. More than half of the participants $(n=1429,56.9 \%)$ reported that they avoided seeking medical care for the fear of being financially burdened. Some participants $(\mathrm{n}=1225,48.7 \%)$ reported difficulties in availing of emergency health care services. Most participants $(n=2171,86.4 \%)$ agreed that the working hours of clinics needed to be extended; however, approximately $1264(50.4 \%)$ reported that it was easy to interact with physicians and nurses during health care counseling, and the remaining 1248 (49.6\%) participants responded with "neutral" or disagreed with the statement, "Interactions with nurses and doctors are easy." The findings of the assessment of the accessibility of health care services are summarized in Table 2. 
Table 2. Accessibility of health care services among the study participants $(\mathrm{N}=2512)$.

\begin{tabular}{ll}
\hline Component & Total, $\mathrm{n}(\%)$ \\
\hline Ease of traveling to the health care center & \\
$\quad$ Very easy & $715(28.5)$ \\
Somewhat easy & $1299(51.7)$ \\
Slightly difficult & $441(17.6)$ \\
$\quad$ Very difficult & $57(2.3)$ \\
Mode of transport to the health care center & \\
Private car & $1140(45.4)$ \\
Friend's or relative's car & $83(3.3)$ \\
Public transport & $93(3.7)$ \\
Taxi or private driver & $1097(43.7)$ \\
Walking & $99(3.9)$
\end{tabular}

How long does it take to reach the health care facility?

$\begin{array}{ll}<15 \text { minutes } & 804(32.0) \\ 15-30 \text { minutes } & 989(39.4) \\ 31-45 \text { minutes } & 362(14.4) \\ 46-60 \text { minutes } & 129(5.1) \\ 1-2 \text { hours } & 132(5.3) \\ >2 \text { hours } & 96(3.8)\end{array}$

If you get sick and need to see a specialist physician, how long does it take to get an appointment?

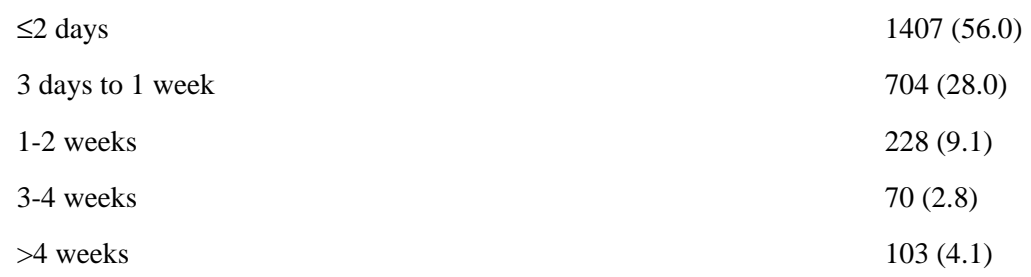

The health care center provides me with the results of all my laboratory tests

$\begin{array}{ll}\text { No } & 615(24.5) \\ \text { Rarely } & 193(7.7) \\ \text { Sometimes } & 536(21.3) \\ \text { Usually } & 568(22.6) \\ \text { Always } & 600(23.9)\end{array}$

If I want to see my medical records, the health care center allows me to have them
No
$1558(62.0)$
Rarely
$172(6.8)$
Sometimes
$276(11.0)$
Usually
207 (8.2)
Always
$299(11.9)$

I find it difficult to cover my medical care costs
Strongly disagree
$42(1.7)$
Disagree
$220(8.8)$
Neutral
$704(28.0)$
Agree
$899(35.8)$
Strongly agree
$647(25.8)$ 


\begin{tabular}{|c|c|}
\hline Component & Total, $\mathrm{n}(\%)$ \\
\hline \multicolumn{2}{|c|}{ I avoid seeking medical care owing to financial concerns } \\
\hline Strongly disagree & $106(4.2)$ \\
\hline Disagree & $396(15.8)$ \\
\hline Neutral & $581(23.1)$ \\
\hline Agree & $746(29.7)$ \\
\hline Strongly agree & $683(27.2)$ \\
\hline \multicolumn{2}{|c|}{ I find it challenging to obtain prompt medical counseling in emergencies } \\
\hline Strongly disagree & $83(3.3)$ \\
\hline Disagree & $392(15.6)$ \\
\hline Neutral & $812(32.3)$ \\
\hline Agree & $797(31.7)$ \\
\hline Strongly agree & $428(17.0)$ \\
\hline \multicolumn{2}{|c|}{ Hospital care is always accessible without difficulty } \\
\hline Strongly disagree & $119(4.7)$ \\
\hline Disagree & $479(19.1)$ \\
\hline Neutral & $777(30.9)$ \\
\hline Agree & $849(33.8)$ \\
\hline Strongly agree & $288(11.5)$ \\
\hline \multicolumn{2}{|c|}{ I can get medical advice whenever I need it } \\
\hline Strongly disagree & $70(2.8)$ \\
\hline Disagree & $465(18.5)$ \\
\hline Neutral & $842(33.5)$ \\
\hline Agree & $879(35.0)$ \\
\hline Strongly agree & $256(10.2)$ \\
\hline \multicolumn{2}{|c|}{ Working hours of clinics should be further extended } \\
\hline Strongly disagree & $0(0)$ \\
\hline Disagree & $49(2.0)$ \\
\hline Neutral & $292(11.6)$ \\
\hline Agree & $1001(39.8)$ \\
\hline Strongly agree & $1170(46.6)$ \\
\hline \multicolumn{2}{|c|}{ Interactions with nurses and physicians are easy } \\
\hline Strongly disagree & $130(5.2)$ \\
\hline Disagree & $516(20.5)$ \\
\hline Neutral & $602(24.0)$ \\
\hline Agree & $853(34.0)$ \\
\hline Strongly agree & $411(16.4)$ \\
\hline
\end{tabular}

\section{Impact of the COVID-19 Pandemic on the Participants' Health}

$86.8 \%$ ) disagreed with the statement that the lockdown had Only $90(3.6 \%)$ participants agreed that the lockdown had affected their health, while most participants $(n=2207,87.9 \%)$ disagreed with that statement. Most participants $(n=1264$, psychological effects. However, 1531 (60.9\%) participants were worried about being afflicted with COVID-19, and 1974 (78.6\%) were worried about their family members becoming infected. Table 3 provides an overview of the effects of COVID-19 on the survey participants. 
Table 3. Effects of the COVID-19 pandemic on the health of the study participants (N=2512).

\begin{tabular}{|c|c|}
\hline Component & Total, n (\%) \\
\hline \multicolumn{2}{|c|}{ The lockdown affected my health } \\
\hline Strongly disagree & $1241(49.4)$ \\
\hline Disagree & $966(38.5)$ \\
\hline Neutral & $215(8.6)$ \\
\hline Agree & $90(3.6)$ \\
\hline Strongly agree & $0(0)$ \\
\hline \multicolumn{2}{|c|}{ The lockdown markedly affected my psychological status } \\
\hline Strongly disagree & $1155(46.0)$ \\
\hline Disagree & $1025(40.8)$ \\
\hline Neutral & $138(5.5)$ \\
\hline Agree & $194(7.7)$ \\
\hline Strongly agree & $0(0)$ \\
\hline \multicolumn{2}{|c|}{ Are you worried about getting COVID-19? } \\
\hline Yes & $1531(60.9)$ \\
\hline No & $981(39.1)$ \\
\hline \multicolumn{2}{|c|}{$\begin{array}{l}\text { Are you worried about the current government policies and responses of the society members to prevent and control the spread of COVID- } \\
\text { 19? }\end{array}$} \\
\hline Yes & $2004(79.8)$ \\
\hline No & $508(20.2)$ \\
\hline
\end{tabular}

\section{Mental Health Outcomes}

In total, 454 (18.1\%) participants had scores of $\geq 15$ on the PHQ-9, which indicates that they had symptoms of depression. Furthermore, 382 (15.2\%) participants had scores of 20-27 on the PHQ-9, which indicated a high likelihood among these participants to experience symptoms of depression. In addition, 372 (14.8\%) participants had scores of $\geq 15$ on the 7 -item Generalized Anxiety Disorder scale, which indicates that they had anxiety symptoms.

\section{Telehealth Usability}

Approximately half of the survey respondents agreed on the usefulness of telehealth services during the COVID-19 pandemic. In addition, more than half of the study participants reported that it was easy to avail of telehealth services and trusted this type of health care service. More than half of the study participants $(n=1435,57.1 \%)$ reported that they felt comfortable seeking the telehealth services, and 1389 (55.3\%) reported that the system was easy to understand. Furthermore, 1354 (53.9\%) participants reported that they could easily communicate with physicians through the telehealth system. However, only 1018 (40.5\%) participants reported that communication with physicians was easier through the telehealth system than through other traditional methods. Regarding the reliability of the system, 1034 (41.2\%) participants reported that the efficiency of the system was similar to that of in-person physician consultations, while 1175 (46.8\%) participants responded with "neutral" to this statement. Additionally, 1439 (57.3\%) participants felt comfortable communicating with physicians through the telehealth system, while 1545 (61.5\%) reported that the system provides an effective means of communication when availing health care services. More than half of the participants $(n=1383,55.1 \%)$ felt satisfied with the telehealth system and were willing to use it in future. Table 4 provides an overview of the participants' perception of the usability of telehealth services during the COVID-19 pandemic. 
Table 4. Usability of telehealth services among the study participants ( $\mathrm{N}=2512)$.

\begin{tabular}{|c|c|c|c|}
\hline Component & Agree, n (\%) & Neutral, n $(\%)$ & Disagree, $\mathrm{n}(\%)$ \\
\hline \multicolumn{4}{|l|}{ Usefulness } \\
\hline The telehealth system has improved my access to health care services & $1134(45.1)$ & $1058(42.1)$ & $320(12.7)$ \\
\hline $\begin{array}{l}\text { The telehealth system saves me the time I spend going to a hospital, } \\
\text { clinic, or specialist }\end{array}$ & $1407(56.0)$ & $959(38.2)$ & $146(5.8)$ \\
\hline The telehealth system satisfies all of my health care needs & $1331(53.0)$ & $978(38.9)$ & $203(8.1)$ \\
\hline \multicolumn{4}{|l|}{ Ease of use and learnability } \\
\hline The system is simple and easy to use & $1479(58.9)$ & $877(34.9)$ & $156(6.2)$ \\
\hline It was easy to learn how to use the system & $1348(53.7)$ & $1024(40.8)$ & $140(5.6)$ \\
\hline I trust that I can quickly get results with this system & $1367(54.4)$ & $979(39.0)$ & $166(6.6)$ \\
\hline \multicolumn{4}{|l|}{ Interface quality } \\
\hline Handling this system is very comfortable to me & $1435(57.1)$ & $959(38.2)$ & $118(4.7)$ \\
\hline I like to use this system & $1224(48.7)$ & $1073(42.7)$ & $215(8.6)$ \\
\hline The system is simple and easy to understand & $1389(55.3)$ & $974(38.8)$ & $149(5.9)$ \\
\hline The system is able to perform all the tasks that I want it to perform & $1158(46.1)$ & $1142(45.5)$ & $212(8.4)$ \\
\hline \multicolumn{4}{|l|}{ Interaction quality } \\
\hline I can easily talk to a physician when using the telehealth system & $1354(53.9)$ & $942(37.5)$ & $216(8.6)$ \\
\hline I can clearly hear the doctor when using the telehealth system & $1048(41.7)$ & $1194(47.5)$ & $270(10.7)$ \\
\hline I felt able to express myself effectively & $1129(44.9)$ & $898(35.7)$ & $485(19.3)$ \\
\hline $\begin{array}{l}\text { Seeing a physician through the telehealth system was as easy as having } \\
\text { an in-person consultation }\end{array}$ & $1018(40.5)$ & $1247(49.6)$ & $247(9.8)$ \\
\hline \multicolumn{4}{|l|}{ Reliability } \\
\hline $\begin{array}{l}\text { Physician consultations using the telehealth system were as efficient as } \\
\text { in-person consultations }\end{array}$ & $1034(41.2)$ & $1175(46.8)$ & $303(12.1)$ \\
\hline $\begin{array}{l}\text { If any error occurs when using the system, I can correct the error quickly } \\
\text { and easily }\end{array}$ & $1225(48.8)$ & $1072(42.7)$ & $215(8.6)$ \\
\hline $\begin{array}{l}\text { The system sends messages when errors occur, and that precisely guided } \\
\text { me on how to correct errors }\end{array}$ & $1444(57.5)$ & $902(35.9)$ & $166(6.6)$ \\
\hline \multicolumn{4}{|l|}{ Satisfaction and future use } \\
\hline $\begin{array}{l}\text { I felt comfortable when communicating with a physician through the } \\
\text { telehealth system }\end{array}$ & $1439(57.3)$ & $855(35.2)$ & $188(7.5)$ \\
\hline The telehealth system is an acceptable way to receive health care services & $1545(61.5)$ & $785(31.3)$ & $182(7.2)$ \\
\hline I will use the telehealth service again in the future & $1383(55.1)$ & $949(37.8)$ & $180(7.2)$ \\
\hline In general, I am completely satisfied with the telehealth system & $1451(57.8)$ & $861(34.3)$ & $200(8.0)$ \\
\hline
\end{tabular}

\section{Discussion}

\section{Principal Findings}

This study aimed to assess the accessibility, applicability, and feasibility of telehealth services in Libya during the COVID-19 pandemic. Most study participants reported being able to access health care facilities. However, most participants found it difficult to cover the cost of the health care services, and more than half of them avoided seeking these services owing to the difficulty in covering their costs. Our study participants reported high levels of telehealth usability and applicability. More than half of the participants $(n=1435,57.1 \%)$ reported feeling comfortable using telehealth services, 1389 (55.3\%) reported that the system was easy to use, and 1354 (53.9\%) reported an enhanced level of interaction with health care providers. Furthermore, 1018 (40.5\%) participants reported that communication with physicians was better through the telehealth system than through traditional health care methods, while 1034 $(41.2 \%)$ reported that the telehealth services were equally as efficient as in-person health care services. In addition, our participants experienced moderate levels of symptoms of anxiety $(n=372,14.8 \%)$ and depression $(n=382,15.2 \%)$.

Regarding the accessibility of the telehealth services, most participants did not report any difficulty in in reaching health care facilities or arranging an appointment with a specialist. However, the participants reported difficulties in accessing their laboratory findings and hospital records, which may be influenced by the unavailability of electronic health records in 
most hospitals and the unavailability of laboratory facilities in several major hospitals, where patients have to visit another facility to obtain the results of laboratory tests.

\section{Comparison With Previous Studies}

Our results suggest that the telehealth system potentially provides an alternative to traditional health care services, especially during the COVID-19 pandemic, concurrent with Mclean et al [24] who reported no difference in outcomes between traditional and telehealth services. Telehealth services offer more flexibility in securing appointments and are more comfortable for individuals living far from health care facilities, especially cancer patients or individuals with chronic diseases who might be at increased risk of severe COVID-19 [25,26]. However, further development of telehealth services is needed to supply the demand for several specialties that require a specific eHealth-based health care infrastructure [27]. A recent study from China [28] reported that telemedicine and telehealth services were effective and feasible and allowed for substantial improvement in health care services for patients with COVID-19. Another study from China [29] on the role of internet hospitals in the COVID-19 pandemic reported that telehealth services and internet hospitals can offer essential support in controlling the pandemic by reducing the cross-infection risk, thus curbing the spread of COVID-19. However, several barriers and challenges regarding the implementation of internet hospitals remain, and further studies with large samples are required to focus on testing specific prototype internet hospitals [30].

Another example of the efficiency of telehealth services is based on individuals with diabetes; telemedicine has been reported to substantially improve health-related outcomes among individuals with diabetes [31]. Another study that used big data and artificial intelligence approaches for diabetes care supported this finding [32].

Our study provides an overview of the mental health status of the Libyan population. Mental health services constitute a major application of telehealth, with several smartphone apps yielding positive outcomes during self-management of depression [33]. The demand for these interventions is high, given the current state of mental health during the COVID-19 pandemic, and telehealth facilitates follow-up evaluation of patients with psychiatric disorders without the need for hospital visits. On-demand mental health telehealth systems have shown promising outcomes in reducing the symptoms of depression [34].

Several challenges are associated with the implementation of telehealth services in Libya. The first issue relates to finances. The government and health care authorities need to provide support for telehealth services and provide funding opportunities to help new organizations and health care centers change their traditional approaches for care provision to a remote system to reduce the risk of COVID-19. This is critical because Libya is faced with a financial crisis, and it would be difficult for Libyan residents to cover the cost of such expensive health care services. Second, Libyan residents have been facing problems with electricity provision and internet access over the last few years.
It would be majorly challenging to implement these services during the civil war when internet connectivity is troublesome.

Another issue that needs to be considered in Libya is the protection of patient confidentiality and the ability to devise methods that protect the personal and clinical data of patients. Our study clearly highlights this issue; 1558 (62.0\%) participants reported that they could not access their health reports. However, it is also concerning that several private telehealth services are providing care without any formal agreements or specific policies to protect patient data or let patients access their own health records. Therefore, further studies should address this issue and focus on data protection and on providing patients easy access to their health data.

\section{Strengths and Limitations}

This study has several strengths. First, to our knowledge, this study is the first to validate the Telehealth Usability Questionnaire as an instrument in Arabic. Second, this study is the first to provide an overview of the usability of telehealth and the health status of the Libyan population. Third, our study included a large sample of 2512 individuals with complete data and assessed several health-related issues with a special emphasis on accessibility and the mental health status of the Libyan population. Furthermore, to our knowledge, this study is the first to assess the usability of telehealth services during the COVID-19 pandemic in a transitional, resource-limited country. Our study furthers the current understanding of the usability of telemedicine in transitional, resource-limited countries, and our results support the implementation of telehealth programs despite certain potential challenges associated with them.

The study has several limitations that should be addressed in future studies. First, it was a cross-sectional survey carried out during the COVID-19 pandemic simultaneously with the introduction of telehealth services, and some participants may not have used telehealth services during this period. Second, we did not assess internet connectivity and electricity provision, which are potential factors affecting the ability of some communities to access telehealth services; these factors need to be addressed in future studies. Third, this study was an online cross-sectional survey, and most participants were young and without major comorbidities or chronic diseases; therefore, we may have overestimated the usability of these services because older individuals may face more challenges in using these technologies and may require more assistance. Therefore, further studies are required to assess elderly individuals and those with special needs and to investigate how telehealth systems could be implemented for these specific groups of patients. Fourth, we used self-reported scales, which may have increased the risk of bias. We also used a 3-point Likert scale for the Telehealth Usability Questionnaire; this may have influenced our findings.

\section{Conclusions}

Telehealth services can substantially replace in-person consultations and prevent nosocomial infections in Libya during the COVID-19 pandemic. Our study provides an overview of the accessibility and usability of telehealth services, and our results suggest that telehealth services help reduce the workload 
of physicians and direct contact with patients during the COVID-19 pandemic. Our results support the implementation of telehealth services; however, further studies are required to focus on the protection of patient confidentiality and personal data.

\section{Acknowledgments}

This study did not receive any specific grant from funding agencies in the public, commercial, or not-for-profit sectors.

\section{Authors' Contributions}

ME analyzed and interpreted the data and drafted the manuscript. All authors helped design the study, collect the data, and write the manuscript. All authors read and approved the final manuscript.

\section{Conflicts of Interest}

None declared.

\section{References}

1. Zhou P, Yang X, Wang X, Hu B, Zhang L, Zhang W, et al. A pneumonia outbreak associated with a new coronavirus of probable bat origin. Nature 2020 Mar;579(7798):270-273 [FREE Full text] [doi: 10.1038/s41586-020-2012-7] [Medline: 32015507]

2. Guo Y, Cao Q, Hong Z, Tan Y, Chen S, Jin H, et al. The origin, transmission and clinical therapies on coronavirus disease 2019 (COVID-19) outbreak - an update on the status. Mil Med Res 2020 Mar 13;7(1):11 [FREE Full text] [doi: 10.1186/s40779-020-00240-0] [Medline: $\underline{32169119}$ ]

3. Dong E, Du H, Gardner L. An interactive web-based dashboard to track COVID-19 in real time. Lancet Infect Dis 2020 May;20(5):533-534 [FREE Full text] [doi: 10.1016/S1473-3099(20)30120-1] [Medline: 32087114]

4. Guan W, Ni Z, Hu Y, Liang W, Ou C, He J, China Medical Treatment Expert Group for Covid-19. Clinical Characteristics of Coronavirus Disease 2019 in China. N Engl J Med 2020 Apr 30;382(18):1708-1720 [FREE Full text] [doi: 10.1056/NEJMoa2002032] [Medline: 32109013]

5. COVIDSurg Collaborative. Elective surgery cancellations due to the COVID-19 pandemic: global predictive modelling to inform surgical recovery plans. Br J Surg 2020 Oct;107(11):1440-1449 [FREE Full text] [doi: 10.1002/bjs.11746] [Medline: $\underline{32395848]}$

6. Truog RD, Mitchell C, Daley GQ. The Toughest Triage - Allocating Ventilators in a Pandemic. N Engl J Med 2020 May 21;382(21):1973-1975. [doi: 10.1056/NEJMp2005689] [Medline: 32202721]

7. Mehrotra A, Ray K, Brockmeyer DM, Barnett ML, Bender JA. Rapidly Converting to "Virtual Practices": Outpatient Care in the Era of Covid-19. NEJM Catalyst 2020;1(2) [FREE Full text] [doi: 10.1056/CAT.20.0091]

8. Jones J, Sullivan PS, Sanchez TH, Guest JL, Hall EW, Luisi N, et al. Similarities and Differences in COVID-19 Awareness, Concern, and Symptoms by Race and Ethnicity in the United States: Cross-Sectional Survey. J Med Internet Res 2020 Jul 10;22(7):e20001 [FREE Full text] [doi: 10.2196/20001] [Medline: 32614778]

9. Vandekerckhove P, Vandekerckhove Y, Tavernier R, De Jaegher K, de Mul M. Leveraging User Experience to Improve Video Consultations in a Cardiology Practice During the COVID-19 Pandemic: Initial Insights. J Med Internet Res 2020 Jun 25;22(6):e19771 [FREE Full text] [doi: 10.2196/19771] [Medline: 32519964]

10. Lin C, Tseng W, Wu J, Tay J, Cheng M, Ong H, et al. A Double Triage and Telemedicine Protocol to Optimize Infection Control in an Emergency Department in Taiwan During the COVID-19 Pandemic: Retrospective Feasibility Study. J Med Internet Res 2020 Jun 23;22(6):e20586 [FREE Full text] [doi: 10.2196/20586] [Medline: 32544072 ]

11. Fisk M, Livingstone A, Pit SW. Telehealth in the Context of COVID-19: Changing Perspectives in Australia, the United Kingdom, and the United States. J Med Internet Res 2020 Jun 09;22(6):e19264 [FREE Full text] [doi: 10.2196/19264] [Medline: 32463377]

12. Author. Telemedicine: fad or future? Lancet 1995 Jan 14;345(8942):73-74. [doi: 10.1016/S0140-6736(95)90054-3] [Medline: 7815881]

13. Ohannessian R, Duong TA, Odone A. Global Telemedicine Implementation and Integration Within Health Systems to Fight the COVID-19 Pandemic: A Call to Action. JMIR Public Health Surveill 2020 Apr 02;6(2):e18810 [FREE Full text] [doi: $10.2196 / 18810]$ [Medline: $\underline{32238336}$ ]

14. Dorsey ER, Topol EJ. State of Telehealth. N Engl J Med 2016 Jul 14;375(2):154-161. [doi: 10.1056/NEJMra1601705] [Medline: 27410924]

15. Elhadi M, Msherghi A, Alkeelani M, Alsuyihili A, Khaled A, Buzreg A, et al. Concerns for low-resource countries, with under-prepared intensive care units, facing the COVID-19 pandemic. Infect Dis Health 2020 Nov;25(4):227-232 [FREE Full text] [doi: 10.1016/j.idh.2020.05.008] [Medline: 32631682]

16. Elhadi M, Msherghi A, Alkeelani M, Zorgani A, Zaid A, Alsuyihili A, et al. Assessment of Healthcare Workers' Levels of Preparedness and Awareness Regarding COVID-19 Infection in Low-Resource Settings. Am J Trop Med Hyg 2020 Aug;103(2):828-833 [FREE Full text] [doi: 10.4269/ajtmh.20-0330] [Medline: $\underline{\text { 32563273] }}$ 
17. Elhadi M, Msherghi A. COVID-19 and civil war in Libya: the current situation. Pathog Glob Health 2020 Jul;114(5):230-231. [doi: 10.1080/15575330.2020.1769292] [Medline: 32432976]

18. Eysenbach G. Improving the quality of Web surveys: the Checklist for Reporting Results of Internet E-Surveys (CHERRIES). J Med Internet Res 2004 Sep 29;6(3):e34 [FREE Full text] [doi: 10.2196/jmir.6.3.e34] [Medline: 15471760]

19. Kroenke K, Spitzer RL, Williams JB. The PHQ-9: validity of a brief depression severity measure. J Gen Intern Med 2001 Sep;16(9):606-613 [FREE Full text] [doi: 10.1046/j.1525-1497.2001.016009606.x] [Medline: 11556941]

20. Levis BBTB, Benedetti A, Thombs BD, DEPRESsion Screening Data (DEPRESSD) Collaboration. Accuracy of Patient Health Questionnaire-9 (PHQ-9) for screening to detect major depression: individual participant data meta-analysis. BMJ 2019 Apr 09;365:11476 [FREE Full text] [doi: 10.1136/bmj.11476] [Medline: $\underline{\text { 30967483] }}$

21. Spitzer RL, Kroenke K, Williams JBW, Löwe B. A brief measure for assessing generalized anxiety disorder: the GAD-7. Arch Intern Med 2006 May 22;166(10):1092-1097. [doi: 10.1001/archinte.166.10.1092] [Medline: 16717171]

22. Parmanto B, Lewis AN, Graham KM, Bertolet MH. Development of the Telehealth Usability Questionnaire (TUQ). Int J Telerehabil 2016;8(1):3-10 [FREE Full text] [doi: 10.5195/ijt.2016.6196] [Medline: 27563386]

23. Zhou L, Bao J, Setiawan IMA, Saptono A, Parmanto B. The mHealth App Usability Questionnaire (MAUQ): Development and Validation Study. JMIR Mhealth Uhealth 2019 Apr 11;7(4):e11500 [FREE Full text] [doi: 10.2196/11500] [Medline: 30973342]

24. McLean S, Sheikh A, Cresswell K, Nurmatov U, Mukherjee M, Hemmi A, et al. The impact of telehealthcare on the quality and safety of care: a systematic overview. PLoS One 2013;8(8):e71238 [FREE Full text] [doi: 10.1371/journal.pone.0071238] [Medline: 23977001]

25. Tashkandi E, Zeeneldin A, AlAbdulwahab A, Elemam O, Elsamany S, Jastaniah W, et al. Virtual Management of Patients With Cancer During the COVID-19 Pandemic: Web-Based Questionnaire Study. J Med Internet Res 2020 Jun 24;22(6):e19691 [FREE Full text] [doi: 10.2196/19691] [Medline: 32501807]

26. Khairat S, Meng C, Xu Y, Edson B, Gianforcaro R. Interpreting COVID-19 and Virtual Care Trends: Cohort Study. JMIR Public Health Surveill 2020 Apr 15;6(2):e18811 [FREE Full text] [doi: 10.2196/18811] [Medline: 32252023]

27. Cruz-Martínez RR, Wentzel J, Asbjørnsen RA, Noort PD, van Niekerk JM, Sanderman R, et al. Supporting Self-Management of Cardiovascular Diseases Through Remote Monitoring Technologies: Metaethnography Review of Frameworks, Models, and Theories Used in Research and Development. J Med Internet Res 2020 May 21;22(5):e16157 [FREE Full text] [doi: 10.2196/16157] [Medline: 32436852]

28. Hong Z, Li N, Li D, Li J, Li B, Xiong W, et al. Telemedicine During the COVID-19 Pandemic: Experiences From Western China. J Med Internet Res 2020 May 08;22(5):e19577 [FREE Full text] [doi: 10.2196/19577] [Medline: 32349962]

29. Gong K, Xu Z, Cai Z, Chen Y, Wang Z. Internet Hospitals Help Prevent and Control the Epidemic of COVID-19 in China: Multicenter User Profiling Study. J Med Internet Res 2020 Apr 14;22(4):e18908 [FREE Full text] [doi: 10.2196/18908] [Medline: 32250962]

30. Li P, Luo Y, Yu X, Wen J, Mason E, Li W, et al. Patients' Perceptions of Barriers and Facilitators to the Adoption of E-Hospitals: Cross-Sectional Study in Western China. J Med Internet Res 2020 Jun 11;22(6):e17221 [FREE Full text] [doi: 10.2196/17221] [Medline: 32525483]

31. Timpel P, Oswald S, Schwarz PEH, Harst L. Mapping the Evidence on the Effectiveness of Telemedicine Interventions in Diabetes, Dyslipidemia, and Hypertension: An Umbrella Review of Systematic Reviews and Meta-Analyses. J Med Internet Res 2020 Mar 18;22(3):e16791 [FREE Full text] [doi: 10.2196/16791] [Medline: 32186516]

32. Musacchio N, Giancaterini A, Guaita G, Ozzello A, Pellegrini MA, Ponzani P, et al. Artificial Intelligence and Big Data in Diabetes Care: A Position Statement of the Italian Association of Medical Diabetologists. J Med Internet Res 2020 Jun 22;22(6):e16922 [FREE Full text] [doi: 10.2196/16922] [Medline: 32568088]

33. Firth J, Torous J, Nicholas J, Carney R, Pratap A, Rosenbaum S, et al. The efficacy of smartphone-based mental health interventions for depressive symptoms: a meta-analysis of randomized controlled trials. World Psychiatry 2017 Oct;16(3):287-298 [FREE Full text] [doi: 10.1002/wps.20472] [Medline: 28941113]

34. Kunkle S, Yip M, $\Xi$ W, Hunt J. Evaluation of an On-Demand Mental Health System for Depression Symptoms: Retrospective Observational Study. J Med Internet Res 2020 Jun 18;22(6):e17902 [FREE Full text] [doi: 10.2196/17902] [Medline: $\underline{32554387]}$
Abbreviations
PHQ-9: 9-item Patient Health Questionnaire 
Edited by G Eysenbach; submitted 08.08.20; peer-reviewed by I Prieto-Egido, B Bente; comments to author 22.09.20; revised version received 06.10.20; accepted 05.12.20; published 26.02.21

Please cite as:

Elhadi M, Msherghi A, Elhadi A, Ashini A, Alsoufi A, Bin Alshiteewi F, Elmabrouk A, Alsuyihili A, Elgherwi A, Elkhafeefi F, Abdulrazik $S$, Tarek $A$

Utilization of Telehealth Services in Libya in Response to the COVID-19 Pandemic: Cross-sectional Analysis

JMIR Med Inform 2021;9(2):e23335

URL: https://medinform.jmir.org/2021/2/e23335

doi: $\underline{10.2196 / 23335}$

PMID: 33606654

CMuhammed Elhadi, Ahmed Msherghi, Ahmed Elhadi, Aimen Ashini, Ahmed Alsoufi, Fatimah Bin Alshiteewi, Amna Elmabrouk, Ali Alsuyihili, Alsafa Elgherwi, Fatimah Elkhafeefi, Sarah Abdulrazik, Ahmed Tarek. Originally published in JMIR Medical Informatics (http://medinform.jmir.org), 26.02.2021. This is an open-access article distributed under the terms of the Creative Commons Attribution License (https://creativecommons.org/licenses/by/4.0/), which permits unrestricted use, distribution, and reproduction in any medium, provided the original work, first published in JMIR Medical Informatics, is properly cited. The complete bibliographic information, a link to the original publication on http://medinform.jmir.org/, as well as this copyright and license information must be included. 